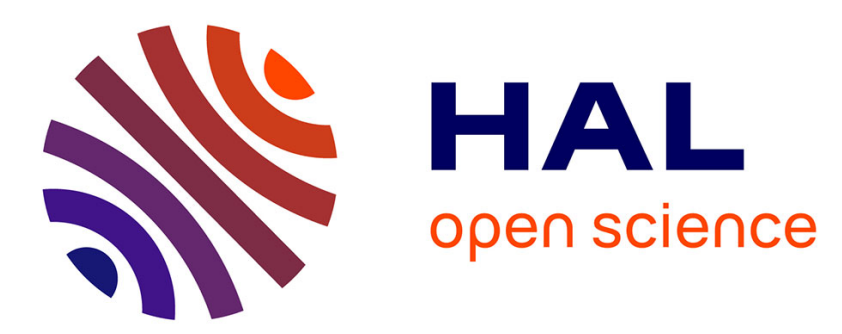

\title{
Simulating the morphology of barley spike phenotypes using genotype information
}

Gerhard G. Buck-Sorlin, Konrad Bachmann

\section{To cite this version:}

Gerhard G. Buck-Sorlin, Konrad Bachmann. Simulating the morphology of barley spike phenotypes using genotype information. Agronomie, 2000, 20 (6), pp.691-702. 10.1051/agro:2000161 . hal00886072

\section{HAL Id: hal-00886072 \\ https://hal.science/hal-00886072}

Submitted on 1 Jan 2000

HAL is a multi-disciplinary open access archive for the deposit and dissemination of scientific research documents, whether they are published or not. The documents may come from teaching and research institutions in France or abroad, or from public or private research centers.
L'archive ouverte pluridisciplinaire HAL, est destinée au dépôt et à la diffusion de documents scientifiques de niveau recherche, publiés ou non, émanant des établissements d'enseignement et de recherche français ou étrangers, des laboratoires publics ou privés. 


\title{
Simulating the morphology of barley spike phenotypes using genotype information
}

\author{
Gerhard Hartwig BucK-SoRLIN*, Konrad BACHMANN \\ Institute of Plant Genetics and Crop Plant Research, Corrensstr. 3, 06466 Gatersleben, Germany
}

(Received 17 February 2000; accepted 31 May 2000)

\begin{abstract}
A computer graphic L-system-model simulating the final morphology of the barley (Hordeum vulgare L.) spike is presented. By applying different parameter sets to growth and branching rules, natural variation in spike morphology can be modelled visually. The biological relevance of the simulated phenotypes is enhanced in various ways: (1) constraints arising from parameter correlations are considered in the growth rules; (2) parameters are chosen to mimic the plant's morphology; (3) their ranges are based on those of real plants. The model is designed to predict and visualize phenotypes corresponding to diploid multigenic genotypes. Those are assembled from lists of alleles belonging to specified genes (or QTLs). Interactions of alleles (dominance, additivity) and of genes (epistasis) are computed from measurements to predict values of morphological variables. Two examples illustrate the principles of the model: spikelet rows and awn length. The use of quantitative data supplied by analysis of QTLs is considered.
\end{abstract}

\section{Hordeum vulgare L. / morphological model / barley / genotype specification / L-system}

Résumé - Simulation de la morphologie des phénotypes de l'épi d'orge à partir de l'information génotypique. Un modèle basé sur des L-systèmes simulant la morphologie finale de l'épi d'orge (Hordeum vulgare L.), est présenté. Les variations naturelles de morphologie de l'épi sont modélisées et reproduites visuellement grâce à l'utilisation de différents jeux de paramètres modifiant les règles de croissance et de ramification. La pertinence biologique des phénotypes simulés est accrue de diverses façons: (1) les contraintes relatives aux corrélations entre paramètres sont prises en considération dans les règles de croissance, (2) les paramètres sont choisis en vue d'imiter la morphologie de la plante, (3) l'étendue de la variation des paramètres repose sur des observations faites sur les plantes réelles. Le modèle vise à prédire et visualiser des phénotypes correspondant à des génotypes diploides multigéniques. Ceux-ci sont créés à partir des listes d'allèles appartenant à des locus spécifiques (ou QTLs). Les interactions entre allèles (dominance/additivité) ou entre gènes (effets epistatiques) sont calculées en utilisant les connaissances fournies par les études génétiques expérimentales et permettent la prédiction des valeurs de variables morphologiques. Deux exemples illustrent les principes du modèle: le nombre de rangs d'épillets et la longueur des barbes. L'intégration dans le modèle des données quantitatives sur les effets des QTLs est envisagée.

Hordeum vulgare L. / modèle morphologique / orge / génotype / L-système

Communicated by Philippe Brabant (Gif-sur-Yvette, France)

* Correspondence and reprints

buck@ipk-gatersleben.de 


\section{Introduction}

A variety of computer models visualize crop development and simulate the phenology of various crops under different conditions of growth. Examples are models for maize [5], for wheat [3] or for sunflower, rapeseed and winter wheat [33]. The relevant variables in these approaches are environmental, with genetic factors not being explicitly considered. These methods can also be adapted to simulate and visualize the phenotypes corresponding to various genotypes. Such a model should provide a geometrically realistic description of the morphology as well as permitting the specification of parameters on the basis of genetic information. Also, gene interactions in phenotypic development should be rendered closely and realistically enough to allow an extrapolation from the phenotypes of known genotypes to the phenotypes specified by gene combinations that have not yet been examined. Here, we introduce a computer graphic model of the barley spike as the first step of a model system which will simulate the morphology and phenology of the entire barley plant. Barley was chosen as it is a long-standing model plant in genetics (e.g. [30]); detailed linkage maps are available from classical segregation studies [7, $31]$ and studies with molecular markers $[2,10,15$, 27].

Earlier mathematical models of barley (Hordeum vulgare L.) have concentrated on developmental processes within the shoot apex, since this determines the final morphology of the barley plant, the arrangement of leaves as well as generative characteristics, such as the number of spikelets per spike. These studies were concerned with biophysical [e.g. 14], phenological [21, 23] or physiological [9] aspects of the growth and development of the barley shoot apex, and showed the difficulties still encountered when trying to explain cellular differentiation and development. In contrast to the approaches presented above, which try to represent developmental mechanisms on a microscale, the aim of our model is to use descriptive quantitative genetic data to predict (mature) phenotypes on a meso-scale for specified genotypes, thereby taking into account gene effects such as dominance, additivity and epistasis. On this rather general level, the model potentially allows the combination and graphical visualization of the knowledge available on gene actions and interactions in complex multigenic genotypes.

\subsection{Morphology of the barley inflorescence}

The barley inflorescence is a false spike, with spikelets on contracted axes (for convenience, we will nevertheless refer to it as a spike in the following). The main inflorescence axis, the so-called rachis, lacks a terminal spikelet. The spikelets are arranged as triplets (one central and two lateral spikelets), alternately attached at nodes on each side of a zig-zag solid rachis, i.e. a triplet of spikelets is not directly attached to the rachis but sits on a short lateral axis, the rachilla. Each spikelet produces a single floret. The florets of the central spikelets are usually fertile and form grains (except in the f. labile from Ethiopia), whereas the fertility of the lateral florets depends on the genotype and maximally leads to the so-called sixrowed barley. The sequence of organs in the spikelet is as follows: two glumes (sometimes with short awns) are attached on either side of the spikelet; a sheath-like lemma with or without an awn of variable length functions as an abaxial envelope; just inside, hidden between the lemma and the gynoeceum, there are two small lodicules. Another sheath, the palea protects the grain on the other, adaxial side, being either attached to it or not. The actual flower consists of three stamens and a gynoeceum with an ovary and a twobranched style [4].

\section{Materials and methods}

\subsection{Description of the morphological model}

Our spike model comprises a complete geometrical description of the organs mentioned above, with some simplifications in the spikelet, where the grain and the lemma as well as all floral organs 
inside are considered as a single object. The spikelet triplets are also assumed to be directly inserted to the main axis, thereby neglecting the rachilla. These simplifications are necessary for modelling economy, and do not convey an unrealistic overall impression of the spike. The model is dynamic in so far as it is possible to independently animate the growth and development of the organs constituting the spike. However, too little usable data is available on the process and timing of spike development in barley for the dynamic model to be realistic at this stage, and we therefore abstain from presenting the dynamic aspect of the model here.

\subsection{L-Systems}

In this work, L(indenmayer)-systems were used as a modelling language as they are the most transparent and flexible method available [19]. L-systems are parallel rewriting systems based on the recurrent application of a set of rules to a string (expression, sentence). During this process, the string usually increases in length and complexity. Such a string normally consists in part of graphically interpretable symbols (modules), which allows its representation as an image at different successive time steps (for further explanations see Refs. [5, 17, 26]).

The L-System models were devised and run using the program cpfg 3.4 within the vlab ${ }^{1}$ environment [26] on two Silicon Graphics workstations.

In our barley model, the L-System proper consists of production rules which determine the initiation, sequence, and development of the organs in the inflorescence. The following scheme shows the modular hierarchical construction of a barley inflorescence in simplified L-system notation:

$$
\begin{aligned}
& p 1: \quad w->m(n) \\
& p 2: \quad m(n): n<=n_{\max ^{-}}>[s] m(n+1),
\end{aligned}
$$

where, in the first production, $w$ denotes the axiom or start word, $m$ the first module, a meristem which, in production 2, produces a lateral spikelet triplet $s$ plus a further meristem symbol $m$. The square brackets [and] symbolize the beginning and end of branching, respectively. This action is repeated as long as the condition in $p 2$ is fulfilled, i.e. the current number of spikelet triplets $n$ is smaller than or equal to, the maximum number of spikelet triplets $n_{\max }$. The rules for the further differentiation of the spikelet triplet into fertile or sterile spikelets depend on the genotype and are not shown here.

\subsection{Parametrization}

For the purpose of this study, parametric L-systems were used throughout. Parameters have to be declared as variables in the L-system file with their name and with a realistic range of values within which one can be chosen as input parameter for a specific simulation. More detailed information on parametric L-systems can be found in Fournier and Andrieu [5] who used a similar approach to ours.

Twelve parameters have been incorporated into the spike morphology model (Tab. I). They were selected following measurements on a number of growing plants as well as herbarium specimens of the doubled-haploid F2 winter barley population W766 (Angora x W704/137) which was grown for two vegetation periods in the field and in the greenhouse. For the model presented here the full genetic variation contained in this population was not considered: this will be the subject of a later publication. Rather, some of its specimens were used as biometrical templates to provide the model with realistic values.

In the vlab, the range of a variable is represented by the length of the slider bar on a panel, its current value by the slider position, which can be modified manually to produce different phenotypes. This is illustrated in Figures 1a-1c where the values of three variables have been modified according to Table II, while keeping all other variables defined for this model constant.

\footnotetext{
${ }^{1}$ http://www.cpsc.ucalgary.ca/projects/bmv/vlab/index.html
} 
Table I. Global parameters used in the spike model.

\begin{tabular}{ll}
\hline Name & Description \\
\hline MAX_SPIKELETS & Number of spikelets per spike \\
RACHIS_ELEMENT_LENGTH & Final size of a rachis segment (spindle element): influences density of the ear \\
DIV_ANGLE & Divergence angle between a median spikelet and the spindle axis \\
LATERAL_FLOWER_ANGLE & Divergence angle between a lateral spikelet and the spindle axis \\
DIV_ANGLE2 & Divergence angle between lateral and median spikelets within the same triplet \\
MAX_SEED_SIZE & Final size of grain \\
AWN_ANGLE & Divergence angle between the awn basis and the grain \\
AWNLENGTH & Final awn length \\
GLUME_LENGTH & Final size of a glume \\
GLUME_ANGLE & Divergence angle between glume and spikelet axis \\
DEFICIENS & Deficiens spike (lateral spikelets rudimentary) \\
ROWS & Number of rows $(6,2$, Intermedium) \\
\hline
\end{tabular}

Table II. Settings for three L-system parameters determining inflorescence form, as shown in Figures 1a-1c.

\begin{tabular}{lccc}
\hline Parameter & $\mathrm{a}$ & $\mathrm{b}$ & $\mathrm{c}$ \\
\hline No. of spikelets & 21 & 38 & 10 \\
rachis element length & 0.5 & 0.3 & 0.7 \\
divergence angle & 30 & 50 & 36 \\
\hline
\end{tabular}

In order to avoid unrealistic phenotypes, correlations between certain parameters have been considered in our model. In doing so, a decision has to be made as to whether these correlations are due to basic physical constraints or resulting from genetic interactions.

\subsection{Choice of parameter combinations by specification of genotypes}

In order to run a phenotype simulation, it is necessary to specify the values of all variables. The latter can be done manually by selecting a combination of values within the ranges given on the parameter panel. However, the purpose of the model is the prediction and visualization of a phenotype for a specified genotype. This is accomplished by determining the genetics of the model parameters with respect to relevant (sets of) genes so that quantitative values for the relevant charac- ters can be computed from the specified genotypes, either using methods of combinatorics (in the case of qualitative inheritance) or statistical methods (regression, in quantitative inheritance).

Genes (known genes or quantitative trait loci, QTLs [18, 32]), from experimental populations) are declared as variables in the L-system. In the diploid barley each gene occurs twice, thus we need two variables, one for each copy of the gene. Each gene variable takes up one of a range of discrete values $(0,1,2, \ldots, n)$, depending on the number of alleles it possesses. The user specifies a genotype for a given set of genes by choosing the desired allele combination on a panel. The settings specified on the panel are then sent (as a combination of numbers) to the L-system where they are used to compute the phenotype. Since the two variables representing a gene locus can be modified independently, homozygous as well as heterozygous genotypes can be specified. The following examples (written in C-preprocessor code) illustrate how the genotype information specfied on the panel is used to compute the phenotype in the Lsystem, depending upon the type of inheritance of the genes:

\subsubsection{Dominance}

$$
\begin{aligned}
& \text { \#define G1 } 0 \\
& \text { \#define G2 } 0 \\
& \text { \#define G G1 + G2 }
\end{aligned}
$$



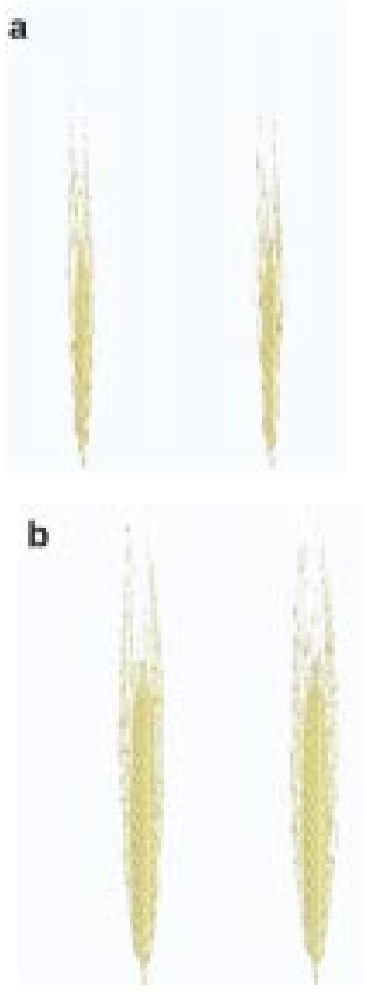

c

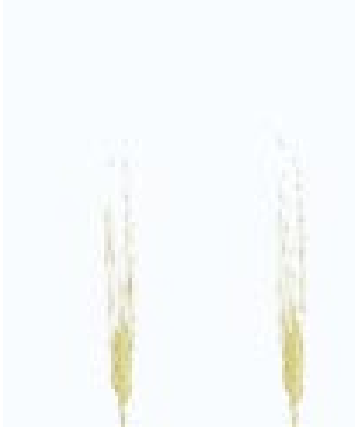

Figure 1. Simulated barley ears. Three parameters (see Tab. II) were varied while all others were set constant. The ears are presented as stereoscopic pairs in order to emphasize that they are not merely flat pictures but 3-D simulations that can be viewed from any angle, and animated.

$\begin{aligned} & \text { \#if } \mathrm{G}>= \\ & \text { \#else } \\ & \text { \#define M } 40 \\ & \text { \#endif. }\end{aligned}$
\#define M 20

G1 and G2 represent the two copies of the gene G and have two states (alleles): 0 and 1. In the example above, both have been set to 0 . G controls the value of the morphological character $\mathrm{M}^{2}$. It can easily be seen from the condition that allele 1 is dominant over allele 0 , as $\mathrm{M}$ will take on the specified larger value if at least one copy of allele 1 is present, and only the smaller value if both copies of $\mathrm{G}$ exhibit allele 0 (homozygosity, as in the example above). This is a typical case of monogenic, dominant inheritance, for which an example (awn length) is provided in the Results section below.

\subsubsection{Additivity}

Alternatively, alleles may act additively to produce an effect of continuous variation, as shown in the following example:

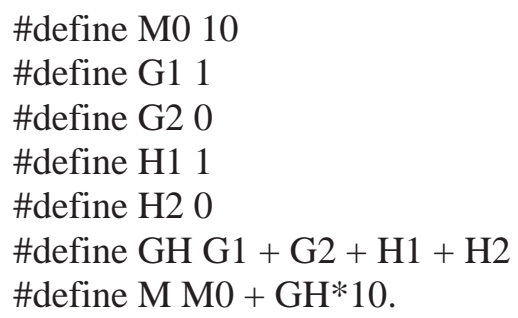

Here, the character $\mathrm{M}$ is determined by two genes, $\mathrm{G}$ and $\mathrm{H}$, each with an inactive (0) and an active (1) allele. Each active allele of $\mathrm{G}$ and $\mathrm{H}$ contributes a value of 10 to the predicted phenotype $M$, thus the value of $M$ is equal to the sum of all active alleles, multiplied by ten. If $\mathrm{G}$ and $\mathrm{H}$ exhibit only inactive alleles, $\mathrm{M}$ will still adopt a basic value of M0.

\subsubsection{Epistasis}

In addition, the allele combination (genotype) of one gene may affect the expression of another gene. This is referred to as epistasis. A simple example for this is given in the Results section, the number of rows in the barley spike.

\section{\#define D1 1 \\ \#define D2 1 \\ \#define R1 1}

\footnotetext{
${ }^{2}$ In this simplified case, M takes on two discrete values only, whereas in reality it would be a continuous parameter affected in its range by the different alleles of G.
} 


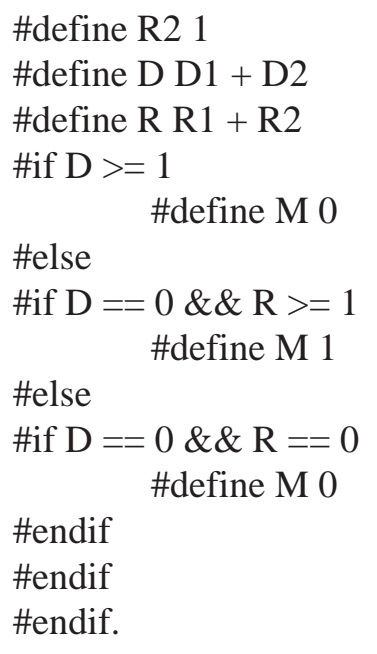

Here, two genes, D and R, each having two alleles, 0 and 1 , control the expression of the morphological character $\mathrm{M}$, which is either present (1) or absent (0). Additionally, D controls the effect of R: if at least one allele 1 of $\mathrm{D}$ is present, $\mathrm{M}$ is not expressed, no matter how many alleles 1 are present at the $\mathrm{R}$ locus. $\mathrm{M}$ is expressed only if $\mathrm{D}$ is homozygous ' $0-0$ ' and $\mathrm{R}$ exhibits at least one allele 1 .

\section{Results}

\subsection{Rows in the barley spike}

Figure 2 illustrates four simulated spikes, each with a different "virtual genotype" at the two loci responsible for rows in spikes. According to a simplified hypothesis [11], the nature of rows in the barley spike, i.e. essentially the fertility of the
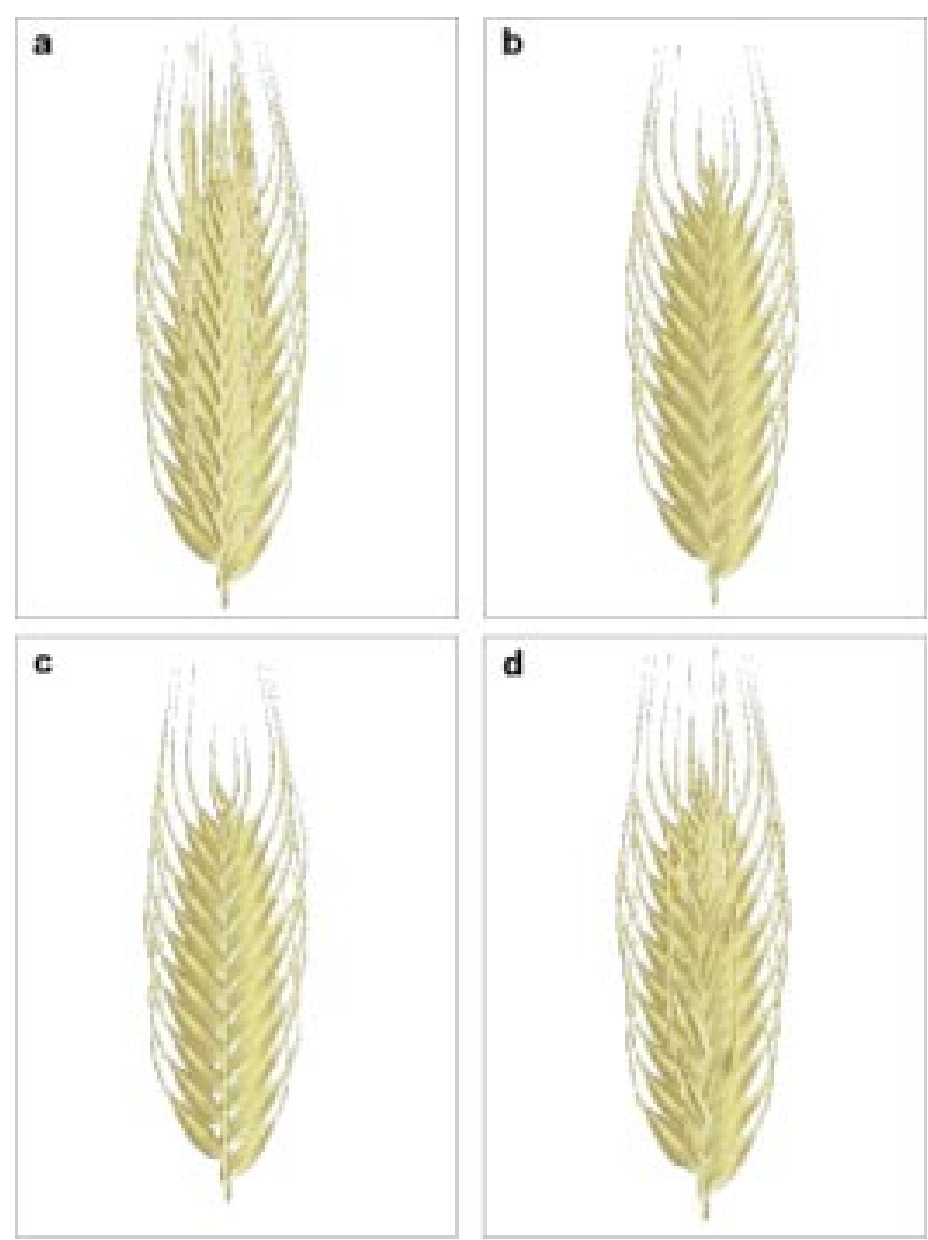

Figure 2. Four simulated barley ears that illustrate the effect of the genes vrs1 and int-c. Whereas vrs1 is responsible for the sterility/fertility of lateral spikelets in the ear, the alleles at the int-c locus influence the size of lateral grains, except when the Vrs1.t allele is present. In the vlab-model, the genotype can be chosen interactively on a panel; the corresponding phenotype is then simulated and animated as a 3-D developmental model. (a) vrs1 vrs1 int-c int-c: hexastichous phenotype. (b) Vrs1 Vrs1 int-c int-c: distichous; (c) Vrs1.t Vrs1.t int-c int-c: Deficiens; (d) Vrs1 Vrs1 Int-c.h Int-c.h: An Intermedium form with 5-60\% fertile lateral spikelets. 
lateral spikelets, depends on two genes, vrs1 and int-c (nomenclature according to [7]: in the following, lower case symbols represent recessive genes, upper case symbols dominant genes), each one of which is representing a multiple allelic series (Vrs1, vrs1, Vrs1.t and Int-c.a, int-c.a, Int-c.h; but see below for the actual nature of the int-c gene). In the first case, vrs1 vrs1 int-c.a int-c.a (Fig. 2a), fully fertile six-rowed inflorescences develop. The genotype Vrs1 Vrs1 int-c int-c (Fig. 2b) gives a two-rowed phenotype, i.e. all lateral spikelets have sterile florets. If the Vrs1.t allele is present on both chromosomes at the vrs 1 locus, in combination with any allele at the int-c locus (e.g. Vrs1.t Vrs1.t int-c int-c), the result is a Deficiens inflorescence, where the lateral spikelets are only rudimentary. In the simulation (Fig. 2c) they are omitted. Finally, there are several "Intermedium" barleys, of which only one possible example, Vrs1 Vrs1 Int-c.h Intc.h, is shown here. The presence of one or two Intc.h alleles here leads to a partial fertility of lateral spikelets, which in this example can lie between 5 and $60 \%$. In the simulation, this is being expressed by randomly choosing a different percentage of fertile spikelets at each programme run, as well as randomly distributing the fertile spikelets along the ear (Fig. 2d). The presence of a Deficiens allele at the vrs1 locus is prohibiting the effect of the int-c gene, simply because the size of a rudimentary spikelet cannot be further modified: an example for epistasis (see above).

The two-factor genotype of the vrs1 and int-c genes affect the L-system by setting the values for two morphological variables, which are then used in the actual growth rules.

The three I-locus genes (int-c.a, Int-c.h and intc.h) included in our model are selected from 41 mutants that have been described for this locus [20]. There is variation among the mutants as regards awn development, fertility and kernel development; this variation is also influenced by environmental conditions. A detailed account is given by Lundqvist and Lundqvist [20].

\subsection{Awn length}

The second example concerns the length of awns attached to the lemma. Genes influencing awn length are quite numerous: more than ten genes located on chromosomes $2 \mathrm{H}, 3 \mathrm{H}, 4 \mathrm{H}, 5 \mathrm{H}$ and $7 \mathrm{H}$ are listed by Nilan [24], Søgaard and Wettstein-Knowles [31] and Franckowiak [8]. These genes chiefly belong to the Lks and breviaristatum-group, in which the short-awned phenotype is recessive to the long-awned type.

Here, the lks2 locus on chromosome $1(7 \mathrm{H})$ was chosen (Fig. 3), as it segregates in the doubledhaploid population W766 that serves as an experi-

Figure 3. Effect of the lks2 gene: simulated barley ears with (a) long (Lks2 Lks2 or Lks2 lks2) and (b) short (lks2 lks2) awns.
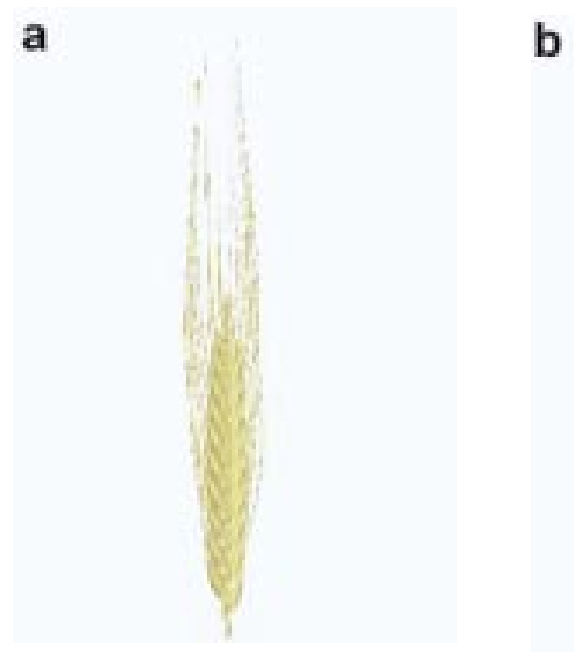
mental control for our model. In this gene, the character 'long awns' (Lks2) is dominant over 'short awns' (lks2), thus the modelling of this characteristic is quite simple.

It becomes more complicated if the Hooded gene Kap is present, a homoeobox gene which causes the formation of a hood (a reversed floret) instead of the awn: the hooded phenotype is dominant, yet it is not expressed in the presence of a homozygous recessive lks2-lks2 (short-awned) genotype [22]. Thus, the short-awned genotype is acting epistatically on the Kap genotype. A parameter declaration for this case would be:

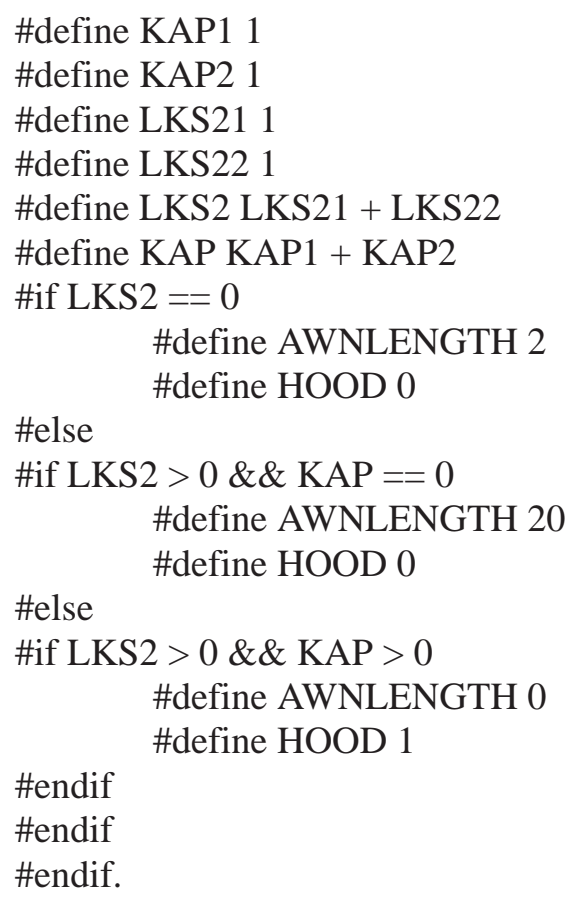

The two genes KAP and LKS2 have two alleles each, 0 and 1, where 0 corresponds to kap and lks2, and 1 to Kap and Lks2, respectively. Three cases are distinguished: (1) The genotype is $1 \mathrm{ks} 2$ lks2 (i.e. LKS2 = 0): then, the morphological parameter AWNLENGTH is set to an (arbitrary) small value and HOOD (symbolizing the presence or absence of a hood) is set to 0 , no matter which alleles are present at the Kap locus. (2) and (3) At least one Lks2 allele is present (LKS2 > 0): then, in case (2) if there are only recessive kap alleles at the Kap locus (KAP $=0$ ) long-awned phenotypes result (AWNLENGTH 20, HOOD 0). In case (3) at least one Kap allele is present along with at least one Lks2 allele (LKS2 > 0 \&\& KAP > 0): only in this case a hood will be formed (AWNLENGTH 0 , HOOD 1).

\subsection{Extension to the simulation of quantitative genetics}

Earlier, we gave an example for a parameter declaration describing additive gene effects. Since for our model it does not matter whether the variables defined as genes are in fact real genes or just pointers to supposed genes, as is the case with QTLs, we can easily extend our model to describe quantitative inheritance. Suppose, for instance, that by analysing our mapping population we found four QTLs (each with two alleles 0 and 1) for the metric parameter $\mathrm{M}$, which described around 50 per cent of the variation found in $M$, the remainder being due to environmental influences (e.g. fertilization, water, etc.). It turns out, say, that there is one main gene Q1 and three modifying genes Q2 to Q4, with the latter only having an effect in the absence of "1" alleles in Q1. Now, the calculation of $\mathrm{M}$ from the various QTL genotype combinations is done using two regression equations. The parameter declaration looks like this:

\#define ENV 10
\#define M0 10
\#define Q11 1
\#define Q12 1
\#define Q21 1
\#define Q22 1
\#define Q31 1
\#define Q32 1
\#define Q41 1
\#define Q42 1
\#define Q1 Q11 + Q12
\#define Q2 Q21 + Q22
\#define Q3 Q31 + Q32
\#define Q4 Q41 + Q42
\#if Q1 > 0
\#define M M0 + C1*Q1 + C2*ENV
\#else
\#if Q1 == 0




\author{
\#define $\mathrm{M} \mathrm{M} 0+\mathrm{C} 2 * \mathrm{Q} 2+\mathrm{C} 3 * \mathrm{Q} 3+\mathrm{C} 4 * \mathrm{Q} 4$ \\ $+\mathrm{C} 5^{*} \mathrm{ENV}$ \\ \#endif \\ \#endif.
}

In the first case (at least one allele " 1 " in Q1), M is described by a simple regression of the form $y=a+b x+c e$, where ENV represents the environmental effect, $\mathrm{M} 0$ a base value of $\mathrm{M} ; \mathrm{C} 1$ and $\mathrm{C} 2$ are calculated from the linear regression between the measured values of $M$ in those individuals exhibiting 1 or 2 alleles " 1 " in the Q1 locus. In the second case (no allele "1" in Q1), M is calculated using a multiple regression with $\mathrm{Q} 2$ to $\mathrm{Q} 4$ of the form $\mathrm{y}=\mathrm{a}$ $+\mathrm{bx}_{1}+\mathrm{cx}_{2}+\mathrm{dx}_{3}+\mathrm{fe}$, with the environmental contribution being symbolized by the term fe.

Using methods of quantitative genetics, we can thus specify the parameters for a particular simulation not by setting them directly but by calculating them from genetic input.

\section{Discussion}

The computer simulation of phenotypes (in the form of morphology, phenology or behaviour) using a limited number of basic rules has been an issue since the early days of computing, as the work by Raup and Seilacher [28] shows, who used three simple rules to graphically simulate foraging patterns of ancient sediment feeders.

The descriptive morphological modelling and simulation of barley offers a new method to visualize information on developmental genetics as a 'virtual phenotype' [1]. The present model uses description and interpolation of gene effects on the phenotype as a short-cut to generate predicted phenotypes. Furthermore, it can accommodate information available on gene actions and interactions to compute the most probable morphology. Additionally, it can convert a table of parameter values into a realistic visual representation of the plant or its individual organs.

The visualization of variation in single characters in an otherwise constant genetic background, such as the examples of dominance, additivity and epistasis illustrated above, are attractive educational tools for interactive exercises in basic genetics. Our WWW-page ${ }^{3}$ gives an example of how knowledge on barley genetics could be conveyed. Starting with the picture of the seven barley chromosomes, the user can interactively obtain higherresolution maps of each chromosome containing in their turn links to genes (i.e. morphological mutants); the latter are summarized in eleven groups, for which brief descriptions are given. Most importantly, for some genes pictures and animations of simulated plants can be downloaded.

However, the main object of the model is the assessment of large data sets as they are produced in experimental or practical breeding experiments. The parameter values used in the model have been derived from an experimental population of doubled haploid plants from a cross between two barley strains differing in a number of morphological and phenological characters. The character segregations in this experimental population are being used for a QTL analysis in which the gene loci responsible for the phenotypic differences between the parental plants will be genetically mapped as "quantitative trait loci" (QTLs), and their interactions in the determination of the phenotypic characters will be analysed by standard methods of quantitative genetics [18, 32]. The various QTLs and their interactions can then be used to predict character values in the model, and the resulting predicted phenotypes for various multi-gene genotypes can be compared with the true values measured in the field. This provides a very sensitive test of the accuracy of the prediction and the reliability of the model, when predicting phenotypes from multi-gene genotypes for which no empirical data are available.

At the moment, the model does not include environmental effects on the phenotype. The predicted phenotypes correspond to those encountered under the favourable experimental conditions that the test populations were exposed to. Also, our model does not include gene $\times$ environment interaction, and the environment term presented above in the

\footnotetext{
${ }^{3}$ http://mansfeld.ipk-gatersleben.de/bucksorlin/
} 
example for a quantitative model is described simplistically as a uniformly distributed error term. It has become clear from many studies [16, 29, 34] that $\mathrm{G} \times \mathrm{E}$ interactions play an important role in quantitative inheritance, and our model has to be considerably refined to take into account these effects. Furthermore, a study by Yin et al. [35] on the role of ecophysiological models in QTL analysis showed that even the effect of well-known qualitative genes may be turned insignificant during certain phenological stages which in their turn heavily depend on environmental parameters such as daily effective temperature. It is open to question whether our model can go as far as to calculate those complex interactions of various factors described above. However, it is reasonable to envisage an extension of our model in such a way that it could visualize such data sets, while leaving the bulk of the computation to more powerful statistical packages.

We are aware that our approach is essentially descriptive. Its power lies in the handling of gene interactions and the prediction of results by interpolation from known data. The model contributes little to developmental genetics, but it can be shown (unpublished results) that parametric L-systems are suitable for the representation of recent models that explain flowering in higher angiosperms such as Arabidopsis [12, 25] or wheat and barley [13]. However, in order to model the processes involved more realistically, a 3D-visualization of apical development on the cellular level should be envisaged, e.g. with the graphical cell model map3D by Fracchia [6]. It visually simulates cell growth and division with the help of edge marker binary propagating cellwork OL-systems (mBPCOL-systems). Current disadvantages of such cellular modelling systems are their huge memory requirement (admittedly just a minor technical problem which could be solved by using more powerful computers) and the lack of cell-tocell context sensitivity, i.e. the modelling of matter flow between cells is impossible. On the positive side, L-systems in general are sufficiently easy to use so that modifications to a given model can be implemented quickly and efficiently.
Our model at the moment describes the morphology of single plants, but it would be a relatively easy exercise to extend the model to describe small stands or populations, thereby allowing the synchronous visualization of different genotypes. It could then be used to predict, say, segregation ratios in $\mathrm{F} 2$ populations and thus potentially become a useful tool in the hands of a breeder or research geneticist.

Much progress is still to be made in the field of plant development and we are just beginning to solve the network of interaction of individual genes. It seems on the other hand that algorithms are not yet refined enough to deal with these processes satisfactorily. Graphical models like the one presented here can only try to summarize and integrate some aspects of development and morphology, but perhaps improved visualization tools will be an incentive to the researcher of development, as the understanding of the developmental processes in crop plants remains an important issue for the future.

Acknowledgments. We thank Jan Kim for discussions and decisive ideas when writing some of the LSystem rules. Thanks are also due to Adrian Bell and Roger Ellis for their critical comments on an earlier version of this paper, as well as to the two anonymous referees. Further thanks go to Ursula Tiemann who improved the figures.

\section{References}

[1] Bachmann K., Hombergen E.J., From phenotype via QTL to virtual phenotype in Microseris (Asteraceae): predictions from multilocus marker genotypes, New Phytol. 137 (1997) 9-18.

[2] Becker J., Vos P., Kuiper M., Salamini F., Heun M., Combined mapping of AFLP and RFLP markers in barley, Mol. Gen. Genet. 249 (1995) 65-73.

[3] Boissard P., Valéry P., Akkal N., Helbert J., Lewis P., Paramétrisation d'un modèle architectural de blé au cours du tallage. Estimation des paramètres de structure par photogrammetrie, in: Andrieu B. (Ed.), Sémin. sur la Model. Archit., INRA Editions, Paris, 1997, pp. 213-220.

[4] Bossinger G., Klassifizierung von Entwicklungsmutanten der Gerste anhand einer 
Interpretation des Pflanzenaufbaus der Poaceae aus Phytomeren, Ph.D. thesis, University of Bonn, 1990.

[5] Fournier C., Andrieu B., A 3D architectural and process-based model of maize development, Ann. Bot. 81 (1998) 233-250.

[6] Fracchia F.D., Visualizing two- and three-dimensional models of meristematic growth, Lect. Notes Comput. Sci. 1017 (1995) 116-130.

[7] Franckowiak J.D., Lundqvist U., Konishi T., New and revised names for barley genes, Barley Genet. Newsl. 26 (1996) 4. (http://wheat.pw.usda. gov/ggpages/bgn/26/text261a.html\#4).

[8] Franckowiak J.D., Revised linkage maps for morphological markers in barley, Hordeum vulgare, Barley Genet. Newsl. 26 (1996) 4. (http://wheat. pw.usda. gov/ggpages/bgn/26/text261a.html\#4).

[9] Frank A.B., Bauer A., Temperature effects prior to double ridge on apex development and phyllochron in spring barley, Crop Sci. 37 (1997) 1527-1531.

[10] Graner A., Jahoor A., Schondelmaier J., Siedler H., Pillen K., Fischbeck G., Wenzel G., Herrmann R.G., Construction of an RFLP map of barley, Theor. Appl. Genet. 83 (1991) 250-256.

[11] Harlan J.R., On the Origin of Barley, in: United States Department of Agriculture, Science and Education Administration (Ed.), Barley: Origin, Botany, Culture, Winter Hardiness, Genetics, Utilization, Pests, USDA Agric. Handb. No. 338, Washington D.C., 1979, pp. 10-36.

[12] Haughn G.W., Schultz E.A., Martinez-Zapater J.M., The regulation of flowering in Arabidopsis thaliana: meristems, morphogenesis, and mutants, Can. J. Bot. 73 (1995) 959-981.

[13] Hay R.K.M., Ellis R.P., The control of flowering in wheat and barley: what recent advances in molecular genetics can reveal, Ann. Bot. 82 (1998) 541-554.

[14] Hejnowicz Z., Nakielski J., Wloch W., Beltowski M., Growth and development of shoot apex in barley. III. Study of growth rate variation by means of the growth tensor, Acta Soc. Bot. Pol. 57 (1988) 31-50.

[15] Heun M., Kennedy A.E., Anderson J.A., Lapitan N.L.V., Sorrells M.E., Tanksley S.D., Construction of a restriction fragment length polymorphism map for barley (Hordeum vulgare), Genome 34 (1991) 437-447.

[16] Keller M., Karutz Ch., Schmid J.E., Stamp P., Winzeler M., Keller B., Messmer M.M., Quantitative trait loci for lodging resistance in a segregating wheat $\mathrm{X}$ spelt population, Theor. Appl. Genet. 98 (1999) 1171-1182.

[17] Kurth W., Growth Grammar Interpreter GROGRA 2.4. A software tool for the 3-dimensional interpretation of stochastic, sensitive growth grammars in the context of plant modelling. Introduction and reference Manual, Forschungszentrum Waldökosysteme der Universität Göttingen, Ber. Forsch. zent. Waldökosyst. Univ. Gött., Reihe B, Bd. 38, Göttingen, 1994.

[18] Lander E.S., Botstein D., Mapping Mendelian factors underlying quantitative traits using RFLP linkage maps, Genet. 121 (1989) 185-199.

[19] Lindenmayer A., Mathematical models for cellular interaction in development, Parts I and II, J. Theor. Biol. 18 (1968) 280-315.

[20] Lundqvist U., Lundqvist A., Induced intermedium mutants in barley: origin, morphology and inheritance, Hereditas 108 (1988) 13-26.

[21] Ma B.L., Smith D.L., Apical development of spring barley under field conditions in Northeastern North America, Crop Sci. 32 (1992) 144-149.

[22] McCoy S., Corey A., Costa J., Hayes P., Filichkin T., Jobet C., Jones C., Kleinhofs A., Kopisch F., Riera-Lizarazu O., Sato K., Scucz P., Toojinda T., Vales I., The Oregon Wolfe Barleys: latest howling successes, Poster, Oregon State Univ., 1999.

[23] Nicholls P.B., May L.H., Studies on the growth of the barley apex, Austral. J. Biol. Sci. 16 (1963) 561-571.

[24] Nilan R.A., The Cytology and Genetics of Barley 1951-1962, Monogr. Suppl. No. 3, Res. Stud., Wash. State Univ., Pullman, 1964.

[25] Pidkowich M.S., Klenz J.E., Haughn G.W., The making of a flower: control of floral meristem identity in Arabidopsis, Trends Plant Sci. 4 (1999) 64-70.

[26] Prusinkiewicz P., Lindenmayer A., The Algorithmic Beauty of Plants, Springer-Verlag, New York, Berlin, Heidelberg, 1990.

[27] Qi X., Stam P., Lindhout P., Comparison and integration of four barley genetic maps, Genome 39 (1996) 379-394.

[28] Raup D.M., Seilacher A., Fossil Foraging Behavior: Computer Simulation, Science 166 (1969) 994-995.

[29] Singh M., Ceccarelli S., Grando S., Genotype × environment interaction of crossover type: detecting its presence and estimating the crossover point, Theor. Appl. Genet. 99 (1999) 988-995. 
[30] Smith L., Genetics and Cytology of Barley, Bot. Rev. 17 (1951) 1-51; 133-202; 285-355.

[31] Søgaard B., von Wettstein-Knowles P., Barley: Genes and Chromosomes, Carlsberg Res. Commun. 52 (1987) 123-196.

[32] Tanksley S.D., Mapping Polygenes, Ann. Rev. Genet. 27 (1993) 205-233.

[33] Wernecke P., Buck-Sorlin G.H., Diepenbrock W., Combing process- with architectural models: The simulation tool VICA, Syst. Anal. - Model. - Simul. (2000), in press.

[34] Yan X., Zhu J., Xu S., Xu Y., Genetic effects of embryo and endosperm for four malting quality traits of barley, Euphytica 106 (1999) 27-34.

[35] Yin X., Kropff M., Stam P., The role of ecophysiological models in QTL analysis: the example of specific leaf area in barley, Heredity 82 (1999) 415-421. 